\title{
CARACTERÍSTICAS DE LA VINCULACIÓN UNIVERSIDAD-ENTORNO EN LA UNIVERSIDAD NACIONAL DE COLOMBIA*
}

\author{
MARÍA EUGENIA MORALES RUBIANO**, PEDRO EMILIO SANABRIA RANGEL ${ }^{* * * *}$ \& DANIEL CABALLERO MARTÍNEZ ${ }^{* * * * *}$ \\ UNIVERSIDAD MILITAR NUEVA GRANADA
}

Recibido/ Received/ Recebido: 20/01/2014 - Aceptado/ Accepted / Aprovado: 28/08/2014

\begin{abstract}
Resumen
Este artículo tiene por objetivo mostrar las características de la interacción Universidad-Entorno en cinco facultades de la Universidad Nacional de Colombia- UN, Sede Bogotá. Para ello, se tiene como fundamento 42 entrevistas a funcionarios y docentes de la universidad que participan activamente en las tres funciones misionales. Para la revisión se usó la metodología de análisis de discurso a partir de un conjunto de categorías que recogen los elementos de la vinculación con el entorno y la percepción de las condiciones y capacidades para desarrollar dicha interacción. En general se encuentra que las facultades estudiadas presentan similitudes en los elementos básicos de relación con los actores del entorno que demandan el conocimiento generado; las diferencias se encuentran en los puntos de vista del rol que debe asumir la universidad actualmente y son la base de la construcción del perfil que se le quiere dar a la UN, frente a la interacción con la sociedad.
\end{abstract}

Palabras clave: Interacción universidad-entorno, Transferencia de conocimiento, Estrategias de vinculación.

\section{FEATURES OF BONDING ENVIRONMENT-UNIVERSITY AT THE COLOMBIA NATIONAL UNIVERSITY}

\begin{abstract}
The main objective of this article is to show the interaction characteristics of University-environment in five Faculties of the Colombia National University (UN) in Bogotá. For this, it was carried 42 interviews with officials and university professors active in the three missionary functions. The data was analyzed using the discourse analysis methodology from a set of categories that reflect the elements of the relationship with the environment and perception of conditions and capacities to
\end{abstract}

\footnotetext{
* Artículo de investigación derivado del proyecto ECO-919: "Estrategias y experiencias de la vinculación Universidad, Empresa y Estado en la Universidad Nacional de Colombia como referente competitivo para la Universidad Militar Nueva Granada- UMNG". Financiado por la Vicerrectoría de Investigaciones de la Universidad Militar Nueva Granada, vigencia 2012.

** Administradora de Empresas y Magíster en Administración, Universidad Nacional de Colombia. Docente de tiempo completo, Facultad de Ciencias Económicas, Universidad Militar Nueva Granada. Líder del Grupo de Estudios Contemporáneos en Contabilidad, Gestión y Organizaciones, Universidad Militar Nueva Granada. Correo electrónico: maria.morales@unimilitar.edu.co. Tel: (57) (1) 6 500000 Ext. 1306. Dirección postal: Cra. 11 \# 101-80, Bloque C, piso 1, Centro de Investigaciones Económicas, Bogotá (Colombia).

*** Administrador de Empresas y Magíster en Administración, Universidad Nacional de Colombia. Estudiante Doctorado en Bioética, Universidad Militar Nueva Granada. Docente de tiempo completo, Facultad de Ciencias Económicas, Universidad Militar Nueva Granada. Investigador adscrito al Grupo de Estudios Contemporáneos en Contabilidad, Gestión y Organizaciones, Universidad Militar Nueva Granada. Correo electrónico: pedro.sanabria@unimilitar.edu.co

***** Administrador de Empresas, Universidad Nacional de Colombia. Especialista en Gestión del Desarrollo Administrativo, Universidad Militar Nueva Granada. Auxiliar de investigación del Grupo de Estudios Contemporáneos en Contabilidad, Gestión y Organizaciones, Universidad Militar Nueva Granada. Correo electrónico: dkballero@gmail.com
} 
develop such interaction. In general it is found that the powers studied show similarities in the basic elements regarding environmental actors that demand the generated knowledge; the differences are found in the point of view about the role that assume the university at present and they are the base on the construction of the profile that you will want to give to the university, versus the interaction with society.

Keywords: College-environment interaction, Knowledge transfer, bonding strategies.

\title{
CARACTERÍSTICAS DA VINCULAÇÃO UNIVERSIDADE-CONTEXTO NA UNIVERSIDADE NACIONAL DA COLÔMBIA
}

\begin{abstract}
Resumo
Este artigo tem por objetivo mostrar as características da interação Universidade-Contexto em cinco faculdades da Universidade Nacional da Colômbia - UN, Sede Bogotá. Para isso, tem-se como fundamento 42 entrevistas feitas a servidores públicos e docentes da universidade que participam ativamente nas três funções missionais. Para a revisão usou-se a metodologia de análise de discurso a partir de um conjunto de categorias que reúnem os elementos da vinculação com o contexto $e$ a percepção das condições e capacidades para desenvolver esta interação. Em geral encontra-se que as faculdades estudadas apresentam semelhanças nos elementos básicos de relação com os atores do contexto que demandam o conhecimento gerado; as diferenças encontram-se nos pontos de vista do papel que deve assumir a universidade atualmente e são a base da construção do perfil que se quer dar à UN, frente à interação com a sociedade.

Palavras chave: Interação universidade-contexto, Transferência de conhecimento, Estratégias de vinculação.

Morales, M., Sanabria, P. \& Caballero, D. (2015). Características de la vinculación universidadentorno en la Universidad Nacional de Colombia. En: Revista de la Facultad de Ciencias Económicas de la Universidad Militar Nueva Granada. rev.fac.cienc.econ, XXIII (1).
\end{abstract}

JEL: M14, O33.

\section{Introducción}

El conocimiento, como parte de la competitividad de las regiones, se ha convertido en un recurso esencial que se debe adquirir, formar y recrear a partir de las interacciones de los integrantes de la sociedad. En este sentido, es importante revisar los roles, responsabilidades y espacios de encuentro entre los principales actores sociales, universidades, empresas y Estado, para identificar la forma cómo se gestiona la transferencia del conocimiento hacia los sectores de la sociedad que lo demandan.

En consecuencia, en diferentes épocas, se han propuesto una serie de modelos que intentan explicar las relaciones universidad, empresa, Estado y allanar el campo de comprensión de las dinámicas de vinculación que optimicen el flujo del conocimiento entre los distintos actores sociales. Entre estos modelos, se destaca el propuesto por Etzkowitz (1998) -"Triple Hélice"-, en el cual propone que la universidad, como parte de la infraestructura científica-tecnológica, puede desempeñar un papel fundamental en las sociedades, cada vez más basadas en el conocimiento, a partir de la generación y transferencia de conocimiento e innovación hacia el sector productivo, con el apoyo del Estado. Sin embargo, este deja de lado a sectores de la sociedad que no necesariamente forman parte del sistema productivo o empresarial que pueden llegar a ser usuarios del conocimiento generado. La propuesta de un modelo que incluya a la comunidad, como beneficiaria de la transferencia 
de conocimiento, es necesaria para el análisis global de la vinculación de la universidad con el entorno.

Este artículo busca evidenciar las características de la interacción universidad-entorno en cinco facultades de la Universidad Nacional de Colombia- UN, Sede Bogotá, considerando que en el ámbito universitario, la UN es un referente importante en el país; de forma que, con la revisión de este caso se espera generar una contribución a la comprensión de las interacciones de las instituciones universitarias con su entorno inmediato.

Se presenta, en primer lugar, una descripción de los enfoques cultural y empresarial que concurren, con igual o diferente proporción, a explicar el rol de las universidades frente a la sociedad. Seguidamente se exponen los modelos más representativos sobre la relación universidad y entorno. Luego, se ilustra la metodología que se usó en el desarrollo de la investigación. Después, se presentan los resultados del análisis cualitativo, y por último se encuentran las reflexiones y conclusiones producto de la investigación.

\section{Marco teórico}

\subsection{Enfoques de la vinculación universidad y entorno}

El rol de la universidad ha tenido una interesante evolución a través del tiempo en la medida en que se ha reconocido la importancia que ésta tiene dentro de la sociedad como un agente formador, creador de conocimiento y de desarrollo para una comunidad (Mejía, 2009). Además, en el contexto de América Latina y de los países líderes del mundo contemporáneo, Colombia reconoce que la ciencia y la tecnología, cuyo origen principal es la organización universitaria, representan una de las más modernas y eficaces estrategias de acción inmediata para la construcción del futuro nacional, y es el sustento del desarrollo económico, político, social y cultural (Colciencias, 2006).

No obstante, lo anterior solo podrá ser alcanzado si las políticas del gobierno empiezan a hacerse realmente evidentes en los planes nacionales, regionales y municipales, en la planeación del sector productivo de bienes y servicios, en los planes de desarrollo institucional de las entidades de educación, en las actividades de las entidades sociales y en los programas, emisiones y ediciones de los medios de comunicación (Colciencias, 2006). A esto se debe agregar que las universidades deben aportar a este fin mediante la combinación de altos niveles de calidad y de un máximo compromiso social mediante la prestación de servicios, no a un individuo o un grupo reducido, sino a la sociedad en conjunto, respondiendo mediante estas actividades al objetivo genuino $e$ indiscutible de la universidad y a evidenciar su auténtica responsabilidad social (Younes, 2002; Touriñan, 2005).

De esta forma, en un escenario globalizado y con altos niveles de competitividad en todos los campos de la sociedad: educación, producción, comercio, cultura e información, por mencionar algunos, se ha evidenciado una transformación en cuanto a la generación y gestión del conocimiento, siendo este el recurso que contribuye a la creación de riqueza en el marco de una economía basada en el conocimiento (García, 2008). En este sentido, de acuerdo con las condiciones requeridas actualmente para aumentar los niveles de competitividad, la ciencia y la tecnología han sido concebidas, también en Colombia, como la base del cambio social y cultural que se requiere para lograr la convivencia social y una visión compartida del futuro que está en formación (Colciencias, 2006).

Colciencias $(2006,8)$, afirma que la ciencia y la tecnología han tenido un doble enfoque:

"De una parte, con el conocimiento se ha buscado contribuir de forma directa al desarrollo económico y social del país y, desde este punto de vista, se puede hablar como el sentido utilitarista del conocimiento; pero, de otra, la ciencia y la tecnología en sí mismas están contribuyendo a generar las transformaciones culturales de la sociedad y, desde esta perspectiva, a la cual se puede referir como el sentido humanista del conocimiento". 
Estas dos concepciones son sumamente importantes en la medida en que se complementan mutuamente si se desea trabajar en función de una política científica y tecnológica que tenga relación directa con los desafíos existentes en la sociedad colombiana, como procesos de cambio cultural y social, y de una rápida elevación de la productividad y competitividad de los sectores económicos (Colciencias, 2006).

En este contexto, a las universidades les corresponde un rol protagónico como agentes generadores de conocimiento. Sin embargo, cambiar el enfoque sobre la universidad, que permita concebirla como generadora de conocimiento socialmente útil y transferible, implica revisar su organización, sus capacidades y sus rutinas, con miras a desarrollar nuevas actividades en el interior y nuevas relaciones con la sociedad (Acevedo et al., 2005). Esto demanda comprender con mayor profundidad las implicaciones de cada uno de los enfoques si son considerados de forma aislada.

\subsubsection{Desarrollo económico y social del país (sentido utilitarista del conocimiento: enfoque empresarial)}

De acuerdo con Colciencias (2006), la primera forma de ver el conocimiento, la ciencia y la tecnología implica la aplicación de una propuesta educativa utilitarista (pragmatista), de corte neoliberal y posmoderna en donde la educación y la formación del ser humano se concibe como un proceso idéntico a la capacitación y al adiestramiento, el cual permite, o por lo menos es su intención expresa, una rápida y eficaz incorporación a la vida productiva (Vásquez, Mateos \& Lucero, 2013).

Por supuesto, ésta es una visión relacionada con las necesidades empresariales y del mercado laboral que influye en los contenidos y métodos educativos, en las estructuras académicas y administrativas e, incluso, en los procesos de selección, admisión y evaluación de las universidades. Bajo esta perspectiva empresarial y mercantil, se da primacía a los conocimientos de tipo científico, tecnológico y práctico, se fomenta la competencia y el individualismo basados en el pragmatismo y se fomentan actitudes acríticas y no siempre comprometidas con la sociedad en gene- ral. En esta concepción, el conocimiento se concibe básicamente como una mercancía que adquieren los egresados para que, a su vez, ellos puedan venderla al mejor postor en el mercado de trabajo (Vásquez et al., 2013).

Vásquez et al. $(2013,4)$ consideran importante reconocer que la propuesta educativa pragmatista responde a un cambio fundamental del contexto hacia las sociedades capitalistas postindustriales:

"El «saber», fundamentalmente el conocimiento científico-técnico, aparte de ser mercantilizado, se convierte en la principal fuerza de producción, en sustitución de la materia prima y la mano de obra. Ante este hecho la concepción pragmatista de la educación propone que la universidad abandone la concepción humanista de la búsqueda del enriquecimiento del espíritu para orientarse hacia un sentido tecnocrático: $\mathrm{La}$ función de la universidad ya no se enmarca en un relato emancipador $y / o$ especulativo, ahora se preparan sujetos capaces de aplicar el conocimiento, más que de debatirlo o de generarlo".

Para esta concepción la universidad tiene que subordinarse a los principios y la lógica del mercado (utilitarismo, ganancia, pragmatismo), con lo cual la legitimidad tradicional de las prácticas académicas, basadas en criterios humanistas y racionalistas sobre la verdad, lo justo y lo bello, se abandonan (Vásquez et al., 2013).

Así, una de las mayores y permanentes preocupaciones de la política nacional de ciencia y tecnología ha sido la construcción de una comunidad científico-tecnológica y de innovación que tenga el compromiso de los actores que participan en grupos y centros de investigación, en las universidades y en los procesos de I+D de las empresas (Colciencias, 2006). Por ello, el Sistema Nacional de Innovación de Colombia (SNIC) se diseñó con el propósito de dar respuesta a los retos de la sociedad y del sector productivo del país, frente a los fenómenos de la internacionalización de los mercados, la globalización de la economía y los desarrollos generados por las 
tecnologías de la información, la comunicación y el conocimiento.

En esa lógica, el eje de la articulación de las estrategias del SNIC son las empresas y firmas del sector industrial (en Colombia es generalizado hacer referencia al "sector productivo") interesadas en mejorar la productividad, la competitividad y en participar exitosamente en el mercado mundial (López, 2004).

\subsubsection{Generación de transformaciones culturales de la sociedad (sentido humanista del conocimiento: enfoque cultural)}

En un sentido distinto al anterior, la concepción humanista de la educación, asociada a una visión utópica, propone una educación que da primacía al ser humano. Este enfoque considera la capacitación y el adiestramiento como medios para el logro de otros fines, entre los cuales se encuentran como los más importantes: el desarrollo pleno de todas las capacidades y habilidades humanas y el ejercicio de la libertad. Idea que se presenta como opuesta, y alternativa, a la pragmatista y tecnocrática (Vásquez et al., 2013).

Lo anterior no quiere decir que este enfoque rechace o menosprecie el valor del conocimiento científico y tecnológico, lo que hace es ubicarlo en una justa dimensión; no considerarlo como un fin en sí mismo o como un medio puesto simplemente al servicio del capitalismo y de la creación de valor, sino que lo ve como algo que puede servir para alcanzar el desarrollo más pleno, cabal y propio del ser humano. Bajo esta concepción la vida humana no se restringe a los ámbitos económicos y materiales, desligados de otros aspectos de ésta, sino que supone importante considerar la promoción de la sabiduría, es decir, la formación de seres humanos que incluya una concepción de justicia frente a los fines de la vida y de una concepción de la vida buena, tanto a nivel individual como colectivo (Vásquez et al., 2013).

Por estas razones es que todavía en el marco conceptual de la innovación es posible evidenciar la ausencia de una auténtica cultura que implique una construcción social y una difusión clara, crítica y valorativa del marco conceptual de la innovación, de su significado para la sociedad, de su importancia frente a la competitividad de las organizaciones empresariales y no empresariales y de su impacto social (López, 2004).

\subsection{Modelos de relación universidad y entorno}

El nivel de desarrollo de una región o nación está fundamentado en la calidad y formas de interacción de sus instituciones, por lo tanto, resulta necesario entender la relación entre los principales actores regionales involucrados con la ciencia, la tecnología y la innovación de una sociedad para determinar su papel y el grado de responsabilidad de cada uno en la construcción de economías sostenibles y de constante crecimiento. Para lograrlo, se han concebido modelos que buscan explicar la interacción entre la universidad y los demás actores de su entorno, con el fin de comprender cómo el desarrollo académico, la competencia en el sector empresarial y la regulación estatal se convierten en espacios de convergencia que determinan el avance o estancamiento de las condiciones de vida de la sociedad (Pineda, Morales \& Ortiz, 2011).

Algunos de los modelos más conocidos son: el Triángulo de Sábato (Sábato \& Botana, 1968), los sistemas de innovación (Freeman, 1987; Lundvall, 1997) y el modelo de la triple hélice (Etzkowitz \& Leydesdorff, 1996). En especial este último busca integrar ciencia, tecnología y desarrollo económico bajo el planteamiento según el cual para maximizar la capitalización del conocimiento, la universidad debe integrarse estrechamente con la industria (Etzkowitz \& Leydesdorff, 1996; Etzkowitz, Webster, Gebhardt \& Cantisano, 2000).

\subsubsection{Triángulo de Sábato}

El modelo del Triángulo de Sábato afirma que cualquier política de ciencia y tecnología de un país no será realmente eficiente mientras no se involucren tres partes esenciales: el gobierno, la infraestructura científica tecnológica y el sector productivo (Villaveces, 2006; Sábato, 1979). Cada uno de estos agentes conforma el vértice de un triángulo, en el que existen interrelaciones entre cada vértice y extra relaciones entre cada uno de ellos y su entorno (Ilustración 1). 
Ilustración 1. Triángulo de Sábato`

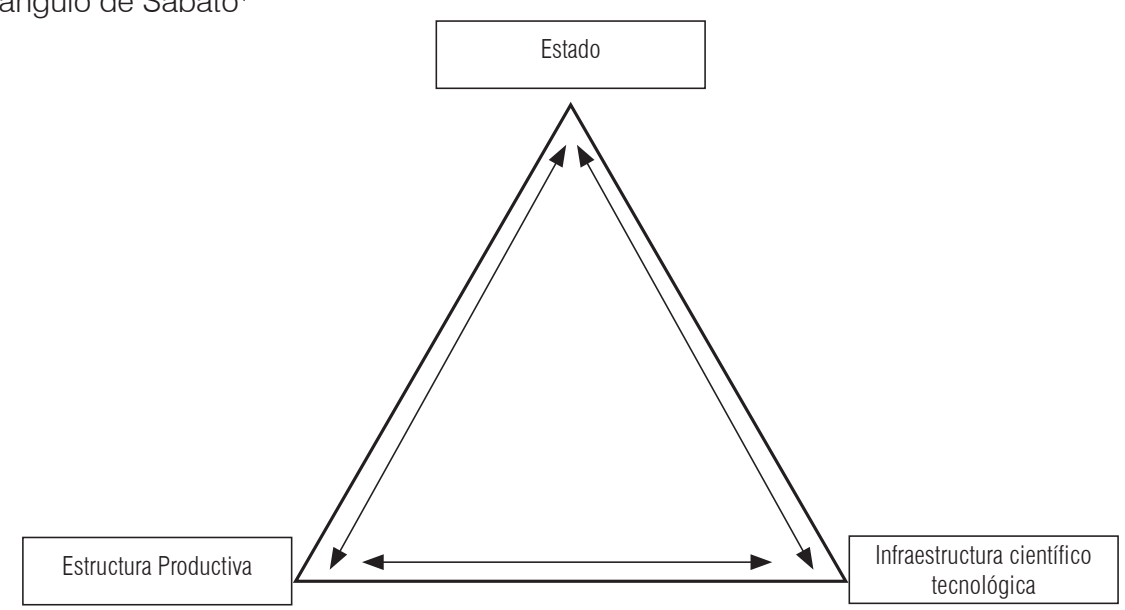

Sábato (1979) muestra el vértice del gobierno como el encargado institucional de la creación de políticas y la movilización de recursos hacia los demás (academia y sector productivo) a través de procesos legislativos y administrativos. El sector productivo es el que se encarga de satisfacer la demanda de bienes y servicios solicitados por una sociedad (Scudelati, 2007). El vértice de la infraestructura científico tecnológica es definido por Scudelati $(2007,3)$ como "Un complejo de elementos articulados e interrelacionados entre sí compuesto por el sistema educativo, laboratorios, centros y plantas piloto, sistema institucional de planificación, mecanismos jurídicos administrativos que reglan el funcionamiento de las instituciones". Es en este último que debido al capital humano que lo compone, se da la mayor parte de la creación del conocimiento en el sistema.

Según este modelo, el gobierno debe incentivar la innovación y favorecerla a través de sus relaciones con los otros dos agentes, promoviendo medidas como: el mejoramiento de la infraestructura física $e$ institucional, facilitando las interrelaciones entre las instituciones a través de mecanismos de coordinación que incentiven la inversión, y financiando innovación tecnológica.

Por su parte, este debe tratar de generar redes que permitan intercambiar experiencias y crear canales de comunicación que posibiliten que cada actor reconozca las demandas y ofertas del otro; con ello se pretende fundamentar una sociedad basada en el conocimiento que propenda por el desarrollo económico sostenible (Scudelati, 2007).

\subsubsection{Sistemas de innovación}

El segundo modelo o marco para la comprensión de la interrelación de los actores es el de los Sistemas de Innovación. Este plantea la integración de diferentes actores de la innovación en estructuras transdisciplinarias e interactivas complejas, donde los agentes y organizaciones se comunican, cooperan y establecen relaciones de largo plazo y condiciones económicas, jurídicas y tecnológicas para el fortalecimiento de la innovación y la productividad de una región o localidad (Pineda et al., 2011). Es conveniente mencionar que uno de los factores que influyó en la creación de este modelo fue la importancia que los organismos internacionales empezaron a darle, durante la última década, a la innovación como fuente de desarrollo de una región mediante el mejoramiento de la competitividad y que reconocería que ésta solo se puede alcanzar mediante la interacción de aquellos agentes que permitan crear y difundir el conocimiento en ella (Buesa et al., 2002). Al interior del modelo, se pueden clasificar los sistemas de innovación en nacionales, regionales y sociales.

1 Fuente: Adaptado de Sábato \& Botana (1968). 
En primera instancia, los Sistemas Nacionales de Innovación se plantearon como un modelo interactivo para promover los procesos de innovación entre agentes institucionales, que se ve favorecido por la globalización y que se caracteriza por la existencia de vínculos o relaciones entre agentes, redes y sistemas de información, condiciones de competencia, incentivos, aprendizaje continuo y el uso y generación de nuevas tecnologías. Generalmente, tanto los procesos de innovación nacionales como los transnacionales provienen de los sistemas regionales, que se van transformando crecientemente en estructuras globalizadas; con el surgimiento del fenómeno de la Región-Estado las firmas globales han visto a las regiones como atractivas para sus actividades (Pineda et al., 2011).

En segunda instancia se encuentran los Sistemas Regionales de Innovación que son mostrados por Buesa (2002) como un conjunto de organizaciones empresariales e institucionales que interactúan entre sí, en un determinado espacio geográfico, con el fin de destinar y administrar recursos que sirvan para la creación y difusión del conocimiento, por cuanto se considera que es en este en el que pueden soportarse las innovaciones y por ende el desarrollo económico.

En este modelo se reconocen tres grupos de organizaciones (Buesa, 2002):

- Las que participan directamente en la generación del conocimiento, como las universidades, los organismos de la investigación y las empresas innovadoras que tengan procesos de investigación y desarrollo, entre otros.

- Las que facilitan las interacciones entre las primeras para favorecer el flujo de la información y la cooperación entre ellas; un ejemplo son los centros y parques tecnológicos, las fundaciones universitarias o las agencias de fomento regional.

- Las que canalizan los recursos financieros hacia los proyectos innovadores. Acá se encuentran los gobiernos, quienes ponen recursos a través de sus políticas de tecnología y ciencia, y las empresas privadas, que aportan capital.
Es importante, dentro de este modelo, la existencia y la prominencia de las empresas innovadoras sobre las demás, ya que estas son las encargadas de introducir todo el sistema de innovación que se ha generado en las primeras organizaciones de forma que puedan usarse los nuevos conocimientos para la obtención de bienes y servicios de forma cada vez más eficiente.

Finalmente, está el tercer tipo: los Sistemas Sociales de Innovación. Estos identifican que la producción y distribución de conocimientos es responsabilidad de un conjunto de instituciones con reglas y modos de regulación propios que conforman el "sistema social de innovación"; la política pública de investigación e innovación está constituida por el conjunto de las intervenciones del estado relacionadas con ese sistema, reflejadas en el apoyo a la innovación industrial mediante el establecimiento de interacciones entre las instituciones creadoras y propietarias del conocimiento y el tejido económico, contribución a la formación de investigación, movilización de conocimiento especializado a las políticas públicas, planes estratégicos de alta tecnología en actividades base de la economía y en el espacio cultural, medioambiental y crecimiento de la sociedad a partir de la reflexión y crítica (Barré, 1995, citado en Pedraza, 2013). En este sentido, la innovación se ve influenciada por el capital social que formen las relaciones de los actores del sistema (Arocena \& Sutz, 2009).

\subsubsection{Triple Hélice}

El modelo de Triple Hélice se fundamenta en las relaciones mutuas que se dan entre tres ámbitos específicos: las universidades o actores científicos, las empresas e industrias y el gobierno, asumiendo que la innovación surge de las interacciones mutuas entre esas partes (González de la Fe, 2009).

El modelo parte de la innovación como concepto central, aunque ésta es entendida como un proceso inestable, una novedad aislada que se encuentra centrada en la organización y en la producción de innovaciones relevantes en el ámbito económico y social y por ello se puede afirmar que ese concepto está centrado en los sistemas de innovaciones más que en la innovación sola (González de la Fe, 2009). 
Según González de la Fe $(2009,742)$ citando a Leydesdorff \& Etzkowitz (2000), "los sistemas de innovación se consideran como dinámicas de cambio tanto en los sistemas de producción como en los de distribución y tienen lugar en el seno de las economías basadas en el conocimiento". Estos sistemas, según la Triple Hélice se producen como resultado de las interacciones entre la universidad, las empresas y el gobierno (Ilustración 2).

\section{Ilustración 2. Modelo de la Triple Hélice}

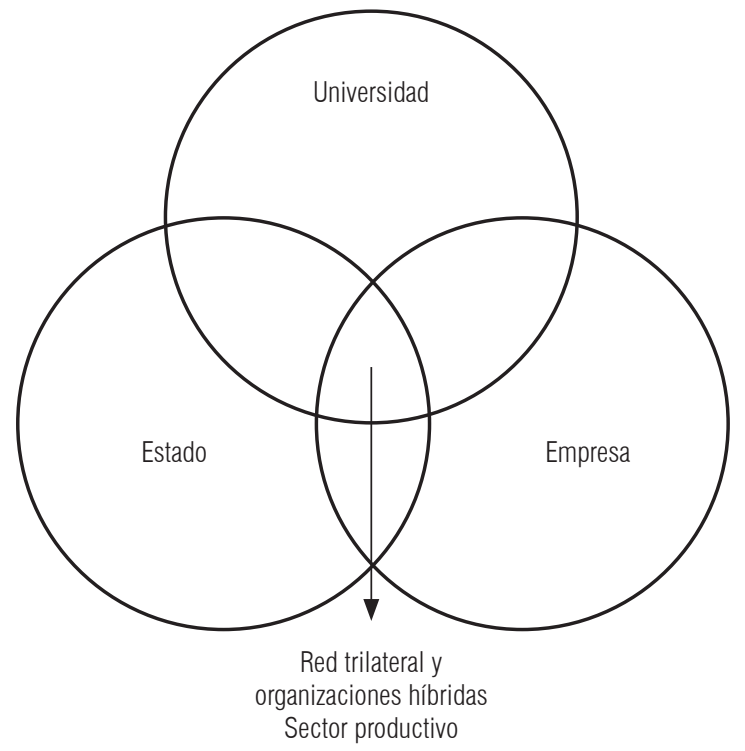

Las innovaciones generadas a través de las interacciones entre los componentes de la Triple Hélice operan a través de dos mecanismos, la asunción institucional de otros roles y la emergencia de organizaciones híbridas (González de la Fe, 2009). Mediante el primero, se suceden cambios y resultados nuevos que se basan en el conocimiento científico (industrias que hacen ciencia, investigadores académicos que crean empresas). En el segundo, las organizaciones híbridas "son el resultado de estos cambios de roles al ser empresas académicas, organizaciones de interfaz o agencias de desarrollo gubernamentales" (González de la Fe, 2009, 743).

Las universidades entonces empiezan a jugar un papel importante dentro del modelo, porque son las que realmente están encargadas de generar las inno- vaciones basadas en el conocimiento. Según Leydesdorff \& Etzkowitz (2000, citados por González de la $\mathrm{Fe}, 2009)$, las universidades deben asumir también la responsabilidad de crear empresas o nidos empresariales desde su interior, para que de esta forma se de paso a la generación de nuevos tipos de universitarios e investigadores: "los científicos empresarios".

Por esta razón el nacimiento de áreas que sirvan como incubadoras dentro de las universidades cobra cada vez más importancia por cuanto, en la actualidad, la creación de nuevos productos y empresas se basa en gran medida en la incubación del conocimiento. Además, esas áreas fortalecen los lazos entre la universidad y la industria, dejando de ser casos empresariales aislados y pasando a la construcción de redes que permitan una mejor interacción entre las partes.

Hay que resaltar que en el modelo de Triple Hélice la generación de la innovación no recae en solo uno de los actores del modelo sino que nace continuamente de las relaciones e interacciones entre los tres, por lo que siempre requerirá de mecanismos y redes que permitan la comunicación entre todos los agentes.

Por tanto, la noción de una Triple Hélice que determina las relaciones universidad, gobierno e industria (Arocena \& Sutz, 2000) se sustenta en los vínculos mutuos que deben darse entre los diferentes actores y para ello toma en cuenta variables sociológicas tradicionalmente descuidadas por la teoría económica (González de la Fe, 2009); el modelo también muestra las interacciones que ocurren para que la universidad, por medio de su conocimiento, transfiera sus desarrollos a las empresas y facilite la innovación en el desarrollo de productos que son esperados para mejorar la calidad de vida de una región. Sin embargo, el modelo considera que esta interacción debe ser apoyada con recursos del gobierno para que sea exitosa (Ramírez \& García, 2010) y debe contemplar la transferencia de conocimiento al conjunto de la sociedad y no solo al sector empresarial.

Teniendo en cuenta que las actividades de las universidades colombianas y en especial las de la Universidad Nacional de Colombia están enmarcadas en los dos enfoques: sentido utilitarista del conocimien- 
to (enfoque empresarial) y sentido humanista del conocimiento (enfoque cultural), y que en ella este último sigue siendo muy fuerte, el modelo de la Triple Hélice no pareciera ser suficiente para interpretar todos los vínculos de la universidad con el entorno. Por esta razón, como se muestra en la Ilustración 3, es necesario evolucionar hacia un modelo del tipo "Tetra Hélice", agregando, como cuarto actor, a la sociedad como usuaria del conocimiento (Brundin, Wigner, Isaacs, Friedrich \& Visser 2008; Ruiz, Castaño, Pastrana, García, Ruiz \& Sagal, 2011).

\section{Ilustración 3. Concepto de Tetra Hélice²}

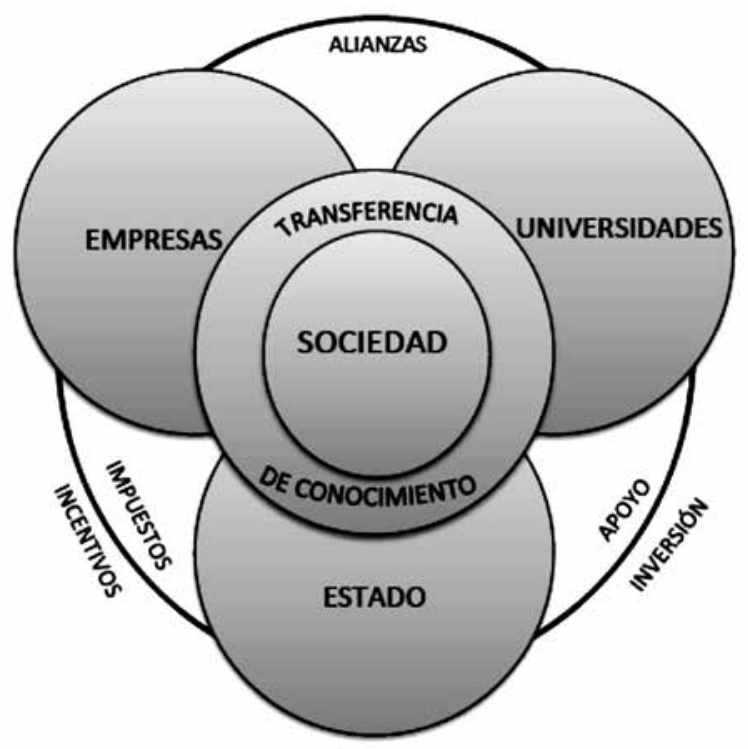

En consecuencia, para la determinación de las características de la vinculación universidad-entorno en la organización analizada y para los propósitos del presente trabajo, se tomó como referente el modelo de Tetra Hélice, porque es el corresponde con lo observado en la institución objeto de la investigación. Se escogió este modelo por incorporar de alguna forma los dos enfoques de vinculación ya señalados y por la preponderancia que le da a la universidad dentro del mismo al ser considerada como el agente encargado de la innovación y la creación de nuevos conocimientos, a diferencia de los otros modelos que, a pesar de incluir a la universidad le dan mayor valor a toda la infraestructura científicotecnológica, incluyendo en ella a los organismos públicos de investigación y a las empresas, con énfasis en investigación y desarrollo, entre otros.

\section{Metodología}

La investigación realizada tiene un enfoque cualitativo, que se enmarca dentro de las ciencias sociales y tomó como método, el estudio de caso (Martínez, 2006). Como técnica para recolectar la información, se utilizó la entrevista semi-estructurada buscando identificar experiencias, estrategias y los mecanismos de la vinculación con el entorno en la Universidad Nacional de Colombia como referente competitivo para otras universidades. Lo anterior en razón a que se reconoce a la Universidad de Antioquia y la Universidad Nacional de Colombia como parte de las universidades pioneras en Colombia en la ejecución de vinculaciones Universidad-Empresa-Estado, cada una de ellas con liderazgo en las regiones donde hacen presencia (Claves para el Debate Público, 2010).

En Bogotá, la Universidad Nacional de Colombia es la coordinadora y ejerce la dirección técnica de la Alianza Universidad-Empresa-Estado Bogotá Región, conformada inicialmente por la Gobernación de Cundinamarca, la Alcaldía de Bogotá, las 11 principales universidades de la ciudad y algunos representantes de la empresa privada, quienes adoptaron el modelo de San Diego - Connect- para establecer una corporación sin ánimo de lucro con el fin de incorporar a la Ciudad Región en el contexto de una economía basada en conocimiento (CONNECT, 2012; UN, 2013). Actualmente están incorporadas 22 universidades y 29 empresas.

Para darle confiabilidad a los resultados, se tomaron varias fuentes de información, a saber: revisión teórica de artículos científicos en revistas indexadas sobre la relación universidad entorno, estudio de documentos institucionales de la UN relacionados con el tema y realización de entrevistas semi-estructuradas a directivos e investigadores de cinco (5) facultades de la Universidad Nacional de Colombia, sede

2 Fuente: Elaboración propia. 
Bogotá: Ciencias Básicas, Ciencias Económicas, Ciencias Políticas y Derecho, Ingeniería y Medicina. La elección de estas cinco facultades obedeció a un criterio de conveniencia en razón a que se buscaba tener un referente para las universidades con facultades que pudieran ser comunes a la mayoría de ellas.

La documentación sobre el régimen legal se obtuvo a través del Sistema de Información Normativa Jurisprudencial y de Conceptos, administrado por la Secretaría General de la UN.

Para la recolección de las experiencias, estrategias y mecanismos usados por las distintas facultades, se realizaron cuarenta y dos (42) entrevistas a profesores y funcionarios vinculados a las mismas durante el periodo 2010-2012, en cargos directivos con cercanía y conocimiento sobre el tema. Los funcionarios entrevistados corresponden a las siguientes dependencias: Decanaturas, Vicedecanaturas Académicas, Vicedecanaturas de Investigación y Extensión, Directores de los Departamentos y Escuelas, Unidades de Educación Continua, Divisiones de Extensión, Oficinas de Relaciones Internacionales y Directores de grupos de investigación. En dichas entrevistas se indagó sobre la relación de las facultades con el entorno en aspectos referidos a cada uno de los ejes misionales de la Universidad Nacional de Colombia: docencia, investigación y extensión.

Posteriormente, el estudio de las entrevistas se realizó tomando como referente el análisis de discurso, usando el sistema de categorías y subcategorías que permiten agrupar en un denominador común varios enunciados dados por los entrevistados sin alterar su sentido (López \& Deslauriers, 2011). Para ello, se elaboró un listado de categorías preliminares obtenido de la revisión de literatura y de categorías emergentes que se configuran al evidenciar su importancia tras el estudio de las entrevistas. De tal modo, el análisis de las entrevistas se basó en cuatro categorías principales (divididas en subcategorías) que recogen las características de estudio sobre la relación de la universidad con el ambiente externo (Tabla 1).
Tabla 1. Categorías de análisis ${ }^{3}$

\begin{tabular}{|c|c|c|c|}
\hline Código & Familias & & Categorías \\
\hline \multirow{3}{*}{ A } & \multirow{3}{*}{ INVESTIGACIÓN } & A.1 & Unidades de enlace \\
\hline & & A.2 & Modalidades \\
\hline & & A.3 & Estrategias \\
\hline \multirow{3}{*}{ B } & \multirow{3}{*}{ DOCENCIA } & B.1 & Unidades de enlace \\
\hline & & B.2 & Modalidades \\
\hline & & B.3 & Estrategias \\
\hline \multirow{3}{*}{ C } & \multirow{3}{*}{ EXTENSIÓN } & C.1 & Unidades de enlace \\
\hline & & C.2 & Modalidades \\
\hline & & C.3 & Estrategias \\
\hline \multirow{2}{*}{ D } & \multirow{2}{*}{$\begin{array}{c}\text { CAPACIDADES } \\
\text { INTERNAS Y } \\
\text { CONDICIONES DEL } \\
\text { MEDIO }\end{array}$} & D.1 & $\begin{array}{l}\text { Percepción de capacida- } \\
\text { des internas para la inte- } \\
\text { racción }\end{array}$ \\
\hline & & D.2 & $\begin{array}{l}\text { Percepción de condicio- } \\
\text { nes del medio para la in- } \\
\text { teracción }\end{array}$ \\
\hline
\end{tabular}

Los conjuntos de categorías se resumen en las funciones misionales o sustantivas de la universidad, añadiendo la percepción tanto sobre las fortalezas como sobre las debilidades de la UN, en particular de las facultades estudiadas, así como también sobre las condiciones del entorno al que pertenece la institución de educación superior. Las subcategorías destacadas en los resultados son aquellas que se mencionaron con mayor frecuencia en las entrevistas.

Los ejes misionales involucran una serie de elementos sintetizados en la condición de la enseñanza universitaria en la búsqueda de la ampliación de conocimientos y el refinamiento de las capacidades de los jóvenes para su perfeccionamiento profesional, la generación de conocimientos a partir de los existentes (aportando alternativas al desarrollo cultural, social y económico de las sociedades) y la apertura hacia la comunidad con el fin de proporcionar elementos técnicos, científicos y artísticos que puedan ser la base de la mejora de las condiciones de vida de todos los integrantes de la sociedad (Pineda et al., 2011; UNESCO, 1998; Younes, 2002).

3 Fuente: Elaboración propia a partir de Morales, Sanabria, Caballero \& Fandiño (2012). 
En este sentido, dentro de las funciones misionales se establecieron como categorías las unidades de enlace, las modalidades y las estrategias. La primera de ellas recoge las dependencias internas e instituciones externas que canalizan la interrelación de las facultades de la universidad con el entorno. Las modalidades se concentran en las formas de interacción institucionales de acuerdo con el eje misional al que corresponden. Finalmente, las estrategias son las acciones formales e informales para la creación y sostenimiento de los vínculos con el entorno.

\section{Resultados}

\subsection{Categorías de análisis por áreas de conocimiento}

El análisis realizado, bajo la perspectiva de las categorías listadas en la Tabla 1, permitió la comparación de las percepciones de las facultades, agrupándolas en áreas de conocimiento. Para ello en el presente trabajo se recurre a la Clasificación Internacional Normalizada de la Educación (CINE) propuesto por la UNESCO (2011) ubicando las facultades en su respectivo Campo de Educación.

\subsubsection{Investigación}

Al realizar el análisis de las entrevistas y la comparación de las áreas de conocimiento se denota una similitud de las características en la vinculación con el entorno (Tabla 2). Las dinámicas de interacción de la universidad con el Estado, empresas y la sociedad usuaria del conocimiento no dejan ver grandes diferencias entre las facultades estudiadas.

\section{- Unidades de enlace}

En las todas las áreas de conocimiento se evidencia que la unidad de enlace con el entorno más reconocida son los grupos de investigación. Lo anterior permite visualizar cómo esta unidad, base de la investigación en una universidad, resulta estratégica en el establecimiento de interacciones con diferentes actores de la sociedad. En Ciencias Básicas y Ciencias Económicas, Políticas y Derecho los centros de investigación se reconocen como puente de conexión que institucionaliza las relaciones con los sectores que demandan los resultados del proceso de investigación. Igualmente, la institucionalidad es visible en las áreas de Ingeniería y Medicina, a través de las Vicedecanaturas que coordinan y centralizan las funciones de interrelación de la academia con los sectores públicos y privados usuarios del saber de dichas facultades.

En contraste, el área de Medicina, por su misma naturaleza se apoya en los hospitales y clínicas universitarias para crear y mantener un vínculo directo con la comunidad usuaria de sus servicios y con el desarrollo de las investigaciones académicas propias del campo del saber.

\section{- $\quad$ Modalidades}

En esta categoría, las cuatro áreas de conocimiento reconocen a la investigación aplicada como la forma de vinculación con el entorno más usada. Más allá de las diferencias propias por la naturaleza de cada campo de conocimiento, estas se identifican por su necesidad de uso de los nuevos conocimientos adquiridos en el desarrollo de la investigación, con el fin de solucionar problemas prácticos.

Por otra parte, la Ingeniería más allá de la aplicación de sus resultados de investigación, se encuentra en continua relación con las necesidades del sector industrial, hecho que se convierte en una oportunidad para los desarrollos experimentales de nuevos materiales, procesos y productos, basados en la mezcla de conocimientos ya existentes y la experiencia práctica de la investigación.

\section{- Estrategias}

Entre las principales estrategias enunciadas por los entrevistados, se observa la realización de convenios o contratos de investigación, seguida de la participación en convocatorias de investigación externas a la universidad. Así mismo, los vínculos informales juegan un papel importante en la relación universidad-entorno y son reconocidos por los académicos e investigadores de las facultades indagadas; en este caso, se evidenció que, con frecuencia, es a través de los vínculos informales que se llega a la realización de convenios o contratos de investigación, lo cual 
Tabla 2. Comparativo investigación - Áreas de conocimiento ${ }^{4}$

\begin{tabular}{|c|c|c|c|c|c|}
\hline & & Ciencias Básicas & $\begin{array}{l}\text { Ciencias Econó- } \\
\text { micas, Políticas y } \\
\text { Derecho }\end{array}$ & Ingeniería & Medicina \\
\hline \multirow[b]{3}{*}{ 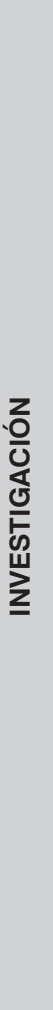 } & $\begin{array}{l}\text { UNIDADES DE } \\
\text { ENLACE }\end{array}$ & $\begin{array}{l}\text { - Grupos de } \\
\text { investigación. } \\
\text { - Centros de } \\
\text { investigación. }\end{array}$ & $\begin{array}{l}\text { - Grupos de } \\
\text { investigación. } \\
\text { - } \text { Vicedecanaturas. } \\
\text { - Centros de } \\
\text { investigación. }\end{array}$ & $\begin{array}{l}\text { - Grupos de investigación. } \\
\text { - Vicedecanaturas. }\end{array}$ & $\begin{array}{l}\text { - Grupos de } \\
\text { investigación. } \\
\text { - Hospitales y clínicas } \\
\text { universitarios. } \\
\text { - } \text { Vicedecanaturas. }\end{array}$ \\
\hline & MODALIDADES & $\begin{array}{l}\text { - Investigación } \\
\text { - } \quad \text { Investicada. } \\
\text { Investigación básica. }\end{array}$ & $\begin{array}{l}\text { - Investigación aplicada. } \\
\text { - Investigación básica. }\end{array}$ & $\begin{array}{l}\text { - Investigación aplicada. } \\
\text { - Desarrollo tecnológico } 0 \\
\text { experimental. }\end{array}$ & $\begin{array}{l}\text { - Investigación } \\
\text { aplicada. } \\
\text { - Investigación básica. }\end{array}$ \\
\hline & ESTRATEGIAS & $\begin{array}{l}\text { - Realización de } \\
\text { convenios o } \\
\text { contratos de } \\
\text { investigación. } \\
\text { - Participación en } \\
\text { convocatorias } \\
\text { de investigación } \\
\text { externas. } \\
\text { - Aprovechar los } \\
\text { vínculos informales } \\
\text { de los académicos o } \\
\text { investigadores. } \\
\text { - Creación de redes } \\
\text { que faciliten el flujo } \\
\text { del conocimiento y } \\
\text { de las finanzas. }\end{array}$ & $\begin{array}{l}\text { - } \text { Realización de } \\
\text { convenios o contratos } \\
\text { de investigación. } \\
\text { - } \text { Adaptar programas } \\
\text { de investigación a } \\
\text { las necesidades de la } \\
\text { industria. } \\
\text { - Participación en } \\
\text { convocatorias de } \\
\text { investigación externas. } \\
\text { - Aprovechar los } \\
\text { vínculos informales } \\
\text { de los académicos } 0 \\
\text { investigadores. }\end{array}$ & $\begin{array}{l}\text { - Participación en convocatorias } \\
\text { de investigación externas. } \\
\text { - Creación de redes que } \\
\text { faciliten el flujo del } \\
\text { conocimiento y de las } \\
\text { finanzas. } \\
\text { - Realización de convenios o } \\
\text { contratos de investigación. } \\
\text { - Aprovechar los vínculos } \\
\text { informales de los académicos } \\
\text { o investigadores. } \\
\text { - Búsqueda de cofinanciación } \\
\text { de tesis de PhD sobre } \\
\text { temas de investigación } \\
\text { definidos por la industria con } \\
\text { contribuciones equivalentes } \\
\text { de la industria y el gobierno } 0 \\
\text { universidad. } \\
\text { Adaptar programas } \\
\text { de investigación a las } \\
\text { necesidades de la industria }\end{array}$ & $\begin{array}{l}\text { - Relación } \\
\text { interfacultades y/0 } \\
\text { con instituciones } \\
\text { académicas para } \\
\text { generar investigación. } \\
\text { - Participación en } \\
\text { convocatorias } \\
\text { de investigación } \\
\text { internas. } \\
\text { - Participación en } \\
\text { convocatorias } \\
\text { de investigación } \\
\text { externas. } \\
\text { - Énfasis en maestrías } \\
\text { y doctorados } \\
\text { (investigación). }\end{array}$ \\
\hline
\end{tabular}

muestra la necesidad de conocer y gestionar estos vínculos por parte de la institución.

En Ciencias Básicas e Ingeniería se observa, además de las estrategias mencionadas anteriormente, la relevancia de la creación de redes que faciliten el flujo del conocimiento y recursos de financiación para investigaciones, principalmente con sectores que patrocinen la labor del desarrollo de nuevos conocimientos aplicados a una necesidad específica. En contraste, en Medicina se percibe la importancia de los lazos externos con instituciones académicas o interfacultades que se convierten en generadores de procesos de investigación al servicio de la comunidad.

\subsubsection{Docencia}

La formación de capacidades profesionales en los estudiantes está limitada por la organización administrativa y académica de cada facultad y los recursos humanos bajo los que opera la labor de docencia. Es decir, para la formación de profesionales exitosos se requieren estudiantes comprometidos bajo la orientación de docentes preparados o idóneos que puedan contar con una óptima infraestructura (Tabla 3).

\section{- Unidades de enlace}

La estructura administrativa y académica de las facultades es un aspecto relevante, según las percep-

4 Fuente: Elaboración propia. 
Tabla 3. Comparativo docencia - Áreas de conocimiento ${ }^{5}$

\begin{tabular}{|c|c|c|c|c|c|}
\hline & & Ciencias Básicas & $\begin{array}{l}\text { Ciencias Económicas, } \\
\text { Políticas y Derecho }\end{array}$ & Ingeniería & Medicina \\
\hline \multirow[b]{3}{*}{ 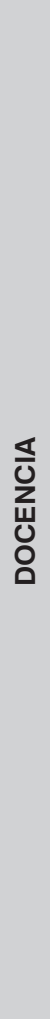 } & $\begin{array}{l}\text { UNIDADES DE } \\
\text { ENLACE }\end{array}$ & - Vicedecanaturas. & $\begin{array}{l}\text { - Escuelas o departamentos } \\
\text { académicos. } \\
\text { - Unidades de emprendimien- } \\
\text { to. }\end{array}$ & $\begin{array}{l}\text { - Oficina de Relaciones Interins- } \\
\text { titucionales. } \\
\text { - Escuelas o departamentos aca- } \\
\text { démicos. }\end{array}$ & $\begin{array}{l}\text { - Hospitales y clí- } \\
\text { nicas universita- } \\
\text { rios. }\end{array}$ \\
\hline & MODALIDADES & - Presencial. & - Presencial. & - Presencial. & - Presencial. \\
\hline & ESTRATEGIAS & $\begin{array}{l}\text { - Conformación de un } \\
\text { equipo de mento- } \\
\text { res expertos en los } \\
\text { campos tecnológico } \\
\text { e innovación, em- } \\
\text { presarial y financia- } \\
\text { miento en capitales } \\
\text { de riesgo. } \\
\text { - Fortalecimiento de } \\
\text { la infraestructura. } \\
\text { - Atraer al proceso de } \\
\text { selección a los me- } \\
\text { jores estudiantes. } \\
\text { - Convocar a docen- } \\
\text { tes del exterior. }\end{array}$ & $\begin{array}{l}\text { - Estimular a una mayor pro- } \\
\text { porción de estudiantes loca- } \\
\text { les a asistir a programas de } \\
\text { intercambio en el exterior. } \\
\text { - Atraer al proceso de selec- } \\
\text { ción a los mejores estudian- } \\
\text { tes. } \\
\text { - Convocar a docentes del } \\
\text { exterior. } \\
\text { - Seleccionar y establecer } \\
\text { relaciones con organiza- } \\
\text { ciones que aporten en el } \\
\text { proceso de formación en los } \\
\text { estudiantes de prácticas y } \\
\text { pasantías. } \\
\text { Relación interfacultades y-0 } \\
\text { con instituciones académi- } \\
\text { cas para generar formación } \\
\text { (programas de pregrado o } \\
\text { posgrado). }\end{array}$ & $\begin{array}{l}\text { - Seleccionar y establecer re- } \\
\text { laciones con organizaciones } \\
\text { que aporten en el proceso de } \\
\text { formación en los estudiantes } \\
\text { de prácticas y pasantías. } \\
\text { - Llevar resultados de investiga- } \\
\text { ción a procesos de formación } \\
\text { - Atraer al proceso de selección a } \\
\text { los mejores estudiantes. } \\
\text { - Convocar a docentes del exte- } \\
\text { rior. } \\
\text { - Seleccionar a los estudiantes } \\
\text { de pregrado y posgrado más } \\
\text { brillantes para enviarlos alrede- } \\
\text { dor del mundo a trabajar como } \\
\text { pasantes en nuevas empresas } \\
\text { de alta tecnología por un año. } \\
\text { - Educación en capacidad em- } \\
\text { presarial a estudiantes y do- } \\
\text { centes. } \\
\text { - Reformas a currículos y planes } \\
\text { de estudios para hacerlos más } \\
\text { flexibles e interdisciplinarios. }\end{array}$ & $\begin{array}{l}\text { - Formación del } \\
\text { personal docen- } \\
\text { te en niveles de } \\
\text { maestrías y doc- } \\
\text { torados. }\end{array}$ \\
\hline
\end{tabular}

ciones de los entrevistados, al indagar por esta categoría. En primer lugar, al interior del área de Ciencias Básicas se observa, debido a la organización de la estructura académica de dicha facultad, que son reconocidas el conjunto de las vicedecanaturas académicas y de investigación como el principal medio de enlace. Dichas unidades, son el canal institucional que permite la centralización de la interrelación de la facultad con el entorno. De forma similar, en las facultades de Ciencias Económicas, Políticas y Derecho se identifican las escuelas o departamentos académicos como las unidades más representativas de las facultades analizadas frente al entorno.
En contraste, para los entrevistados de la Facultad de Ingeniería, la Oficina de Relaciones Interinstitucionales (ORI) es la principal unidad de vinculación con el entorno académico para estudiantes y docentes. La consecución y divulgación de los diferentes convenios con distintas instituciones académicas es la base para la apertura de horizontes en la vida profesional de los estudiantes y de la actualización de currículos y áreas de enseñanza para el docente.

Es necesario destacar la importancia de la unidad de emprendimiento, en la Facultad de Ciencias Económicas, al ser el organismo que acompaña al es-

5 Fuente: Elaboración propia. 
tudiante en su proceso de formación académica y acercamiento al mundo empresarial.

Finalmente y en conformidad con lo descrito por los entrevistados del área de Medicina, los hospitales y clínicas en los cuales los docentes y estudiantes prestan sus servicios durante el proceso de formación se convierten en la unidad de enlace más relevante.

\section{- $\quad$ Modalidades}

Se evidencia, a través de las respuestas de los entrevistados, que la modalidad básica en el aspecto de docencia es la presencial, dadas las características de la Universidad Nacional. Hecho que se confirma con las referencias obtenidas en las diferentes facultades.

\section{- Estrategias}

En tres de las cuatro áreas de conocimiento estudiadas se observa cómo la selección de los estudiantes que ingresan se considera como la base para un exitoso proceso de formación, al igual que el acompañamiento por parte de docentes con experiencia en el exterior o con formación a niveles de maestría y doctorados, como se manifiesta especialmente desde el área de Medicina.

La principal estrategia en Ciencias Básicas, desde la docencia, es la conformación de un equipo de mentores expertos en los campos tecnológico $e$ innovación, empresarial y financiamiento en capitales de riesgo, fundamentado en las necesidades del área de conocimiento en la cual se encuentra la Facultad. En segundo lugar, se encuentra el fortalecimiento de la infraestructura, la cual es vital para una adecuada formación de los estudiantes.

Así mismo, es el estímulo hacia los estudiantes para que participen en los programas de intercambio en el exterior en las facultades de Ciencias Económicas, Políticas y Derecho, la estrategia de mayor referencia. Los programas encaminados a dar a conocer las oportunidades a través de los convenios con universidades del exterior se convierten en una buena práctica para abrir el panorama a los estudiantes con un excelente perfil académico y para incentivar la mejora en el rendimiento académico de los demás estudiantes.
Las facultades de Ciencias Económicas e Ingeniería enuncian como una estrategia relevante, la selección adecuada de las organizaciones que vinculan estudiantes en las modalidades de pasantías y prácticas profesionales, con el fin de garantizar calidad y oportunidad en la aplicación de los conocimientos. Por su parte, no se descuida el traslado a la docencia de los avances logrados en el campo del saber en el despliegue que se realiza para llevar los procesos de investigación hacia las aulas de formación de los estudiantes.

\subsubsection{Extensión}

La extensión, en semejanza con las otras dos funciones misionales, tiene características homogéneas al realizar la comparación por área de conocimiento, a pesar que la esencia de cada campo del saber requiere diversas manifestaciones de relación con el entorno (Tabla 4). En tal sentido, la autonomía de las facultades es necesaria para responder a las problemáticas del mismo.

\section{- Unidades de enlace}

Desde la percepción de los entrevistados, en Ciencias Básicas se denota cómo los enlaces de contacto con el entorno se materializan desde las divisiones de extensión de la facultad. Se resalta el hecho de reconocer, como de gran relevancia, la relación de la universidad con entes externos tales como agencias de desarrollo regional que sirvan como unidades de vinculación de la universidad con la sociedad. En cambio, en la Facultad de Medicina, se determinan como conexión los hospitales universitarios, manteniendo la coherencia del servicio social que prestan.

Por su parte, las facultades de Derecho y Ciencias Económicas destacan como elementos importantes que sirven de contacto con el exterior a los consultorios, hecho que responde a las características del área de conocimiento y su servicio a los actores de la sociedad. De igual forma se encuentran las unidades de emprendimiento como facilitadores para los microempresarios que puedan tener nuevas ideas de negocio. 
Tabla 4. Comparativo extensión - Áreas de conocimiento ${ }^{6}$

\begin{tabular}{|c|c|c|c|c|c|}
\hline & & Ciencias Básicas & $\begin{array}{l}\text { Ciencias Econó- } \\
\text { micas, Políticas y } \\
\text { Derecho }\end{array}$ & Ingeniería & Medicina \\
\hline \multirow[b]{3}{*}{ 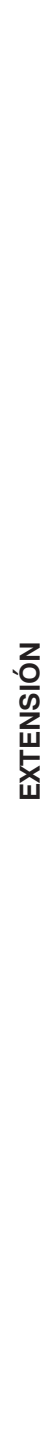 } & $\begin{array}{l}\text { UNIDADES DE } \\
\text { ENLACE }\end{array}$ & $\begin{array}{l}\text { Divisiones de } \\
\text { extensión. } \\
\text { - Agencias de desa- } \\
\text { rrollo regional (ADR) } \\
\text { (CUEE; CARCE; } \\
\text { CRC). }\end{array}$ & $\begin{array}{l}\text { - Consultorios empresa- } \\
\text { riales, jurídicos y cen- } \\
\text { tros de conciliación. } \\
\text { - Unidades de empren- } \\
\text { dimiento. } \\
\text { - Centros o institutos de } \\
\text { investigación. }\end{array}$ & $\begin{array}{l}\text { - Vicedecanaturas. } \\
\text { - ORI -Oficina de Relaciones } \\
\text { Internacionales. } \\
\text { - Centros o institutos de inves- } \\
\text { tigación. } \\
\text { - Oficinas de servicios legales. } \\
\text { - Oficina de prácticas y pasan- } \\
\text { tías. }\end{array}$ & $\begin{array}{l}\text { - Hospitales y clínicas } \\
\text { universitarios. }\end{array}$ \\
\hline & MODALIDADES & $\begin{array}{l}\text { - Prácticas y pasantías } \\
\text { universitarias. } \\
\text { - Participación en } \\
\text { proyectos de in- } \\
\text { novación y gestión } \\
\text { tecnológica. }\end{array}$ & $\begin{array}{l}\text { - Extensión solidaria } \\
\text { - Prácticas y pasantías } \\
\text { universitarias. } \\
\text { - Educación Continua y } \\
\text { - Permanente. } \\
\text { - Servicios Académicos. }\end{array}$ & $\begin{array}{l}\text { - Servicios académicos } \\
\text { - Educación Continua y Perma- } \\
\text { nente. } \\
\text { - Participación en proyectos de } \\
\text { innovación y gestión tecno- } \\
\text { lógica. } \\
\text { - Prácticas y pasantías univer- } \\
\text { sitarias. }\end{array}$ & $\begin{array}{l}\text { - Servicio docente } \\
\text { - } \text { asistencial. } \\
\text { - } \text { univericas y pasantías } \\
\text { - Proyectos de coopera- } \\
\text { ción internacional. } \\
\text { - Participación en pro- } \\
\text { yectos de innovación y } \\
\text { gestión tecnológica. }\end{array}$ \\
\hline & ESTRATEGIAS & $\begin{array}{l}\text { - Divulgación de } \\
\text { resultados de activi- } \\
\text { dades colaborativas } \\
\text { y de investigación. } \\
\text { - Establecer los } \\
\text { alcances de la } \\
\text { contraprestación } \\
\text { por los servicios del } \\
\text { personal docente a } \\
\text { entes externos. } \\
\text { - Realizar contratos de } \\
\text { investigación para } \\
\text { industrias especí- } \\
\text { ficas. } \\
\text { - Participación en } \\
\text { convocatorias y-0 } \\
\text { licitaciones. }\end{array}$ & $\begin{array}{l}\text { - } \text { Realización de contra- } \\
\text { tos y convenios con } \\
\text { organizaciones. } \\
\text { - } \text { Relación interfaculta- } \\
\text { des y-o con institucio- } \\
\text { nes académicas para } \\
\text { generar extensión. } \\
\text { - } \text { Realización de pa- } \\
\text { santías o prácticas } \\
\text { estudiantiles. } \\
\text { - Divulgación de resul- } \\
\text { tados de actividades } \\
\text { colaborativas y de } \\
\text { investigación. } \\
\text { - Ofrecer servicios de } \\
\text { consultorías, asesorías } \\
\text { e interventorías direc- } \\
\text { tamente a organiza- } \\
\text { ciones. } \\
\text { - } \text { Realización programas } \\
\text { de cooperación inter- } \\
\text { nacional. } \\
\text { Movilidad de investi- } \\
\text { gadores a la industria u } \\
\text { otras instituciones. }\end{array}$ & $\begin{array}{l}\text { - Relación interfacultades y-0 } \\
\text { con instituciones académicas } \\
\text { para generar extensión. } \\
\text { - Participación en convocatorias } \\
\text { y-o licitaciones. } \\
\text { - Divulgación de resultados de } \\
\text { actividades colaborativas y de } \\
\text { investigación. } \\
\text { - Aprovechar los vínculos in- } \\
\text { formales de los académicos o } \\
\text { investigadores. } \\
\text { - Realización de contratos y } \\
\text { convenios con organizaciones } \\
\text { Creación y mantenimiento de } \\
\text { relaciones con egresados. } \\
\text { - Hacer ferias, eventos, en- } \\
\text { cuentros, agendas o ruedas } \\
\text { de negocios donde participen } \\
\text { diferentes actores del ScTI. } \\
\text { - Realización de pasantías o } \\
\text { prácticas estudiantiles. } \\
\text { - Aprovechar el buen nombre de } \\
\text { la Universidad. } \\
\text { - Tener buena comunicación con } \\
\text { organizaciones del entorno. }\end{array}$ & $\begin{array}{l}\text { - Realización de contra- } \\
\text { tos y convenios con } \\
\text { organizaciones. } \\
\text { - Establecer los alcances } \\
\text { de la contraprestación } \\
\text { por los servicios del } \\
\text { personal docente a } \\
\text { entes externos. } \\
\text { - Realización de pasan- } \\
\text { tías o prácticas estu- } \\
\text { diantiles. }\end{array}$ \\
\hline
\end{tabular}

En contraste, en la Facultad de Ingeniería, manteniendo un corte institucional ligado a la organización administrativa y académica, se identifican como unidades que sobresalen en la vinculación con el en- torno, la ORI, la Oficina de Prácticas y Pasantías y las vicedecanaturas, en especial la académica, por su responsabilidad en la consecución y seguimiento de oportunidades para los estudiantes en materia de pasantías y prácticas profesionales.

6 Fuente: Elaboración propia. 


\section{- $\quad$ Modalidades}

Las prácticas y pasantías son percibidas como la principal modalidad de extensión en todos los campos de educación indagados. Esto se debe, en gran parte, a la reglamentación uniforme de las modalidades de extensión que rigen a todas las sedes de la Universidad Nacional de Colombia.

En forma seguida, la vinculación que se genera a través de la participación en proyectos de innovación y gestión tecnológica se asume como una modalidad a la cual se le ha prestado atención desde la Facultad de Ciencias.

Ahora, al analizar las formas de vinculación de las facultades de Ciencias Económicas, Políticas y Derecho con el sector externo, se halla que estas se caracterizan por las múltiples formas de interacción. Debido a su carácter de ciencia social, se reconoce a la extensión solidaría como modalidad primordial mientras se denota también la importancia de los servicios tanto académicos como de educación continua y permanente.

De igual modo, y en consecuencia con lo hasta aquí descrito sobre la Facultad de Ingeniería, los servicios académicos son la modalidad de extensión con mayor referencia por parte de los entrevistados, seguido de los servicios de educación continua y permanente. La labor de investigación se refleja en la extensión mediante la participación en proyectos de innovación y gestión tecnológica.

\section{- Estrategias}

Entre las estrategias de extensión usadas, a criterio de los entrevistados, en las diferentes facultades predomina la divulgación de los resultados de actividades colaborativas y de investigación y la realización de contratos y convenios directamente, aunque en cada área de conocimiento se identifican diversas acciones de vinculación.

En primer lugar, en Medicina y Ciencias Básicas, se considera importante establecer los alcances y beneficios que trae consigo la prestación de servicios del personal docente a entes externos, con el fin de delimitar las funciones y responsabilidades del académico sobre la contraprestación a que haya lugar. De igual modo, la vinculación de estudiantes bajo la figura de pasantías o prácticas profesionales es una acción que permite desarrollar un conocimiento formado al servicio de la comunidad. Esta última estrategia es visible también en la Facultad de Ciencias Económicas.

Por su parte, en Ciencias Económicas, por su carácter especialmente dirigido a organizaciones identificadas con un fin económico, se ofrecen servicios de consultorías, asesorías e interventorías directamente a dichas organizaciones. A su vez, se presenta la movilidad de investigadores hacia la industria u otras instituciones.

En otro sentido, el área de Ciencias Básicas referencia que es importante la realización de contratos de investigación para industrias específicas, seguramente como respuesta a las necesidades de financiación expresadas anteriormente.

Por último, en la Facultad de Ingeniería se resaltan una serie acciones estratégicas, desarrolladas como una combinación de fórmulas utilizadas para lograr y mantener relaciones con los actores de la sociedad que rodean al propio campo de conocimiento. En primer lugar esto se realiza con las instituciones académicas y facultades pares. En segunda instancia, la participación en convocatorias y/o licitaciones auspiciadas por entidades públicas. En tercer lugar, se observa la importancia que asumen los medios de divulgación de los resultados de actividades colaborativas y de investigación para dar cuenta del trabajo de la facultad.

\subsubsection{Capacidades y condiciones para la vinculación universidad-entorno}

Cuando se indaga por las capacidades internas y condiciones del entorno se encuentran percepciones divididas sobre las fortalezas y debilidades internas, al igual que las oportunidades y amenazas que existen en el entorno inmediato (Ilustración 4). En el momento de tomar los aspectos con mayor referencia, en opinión de los entrevistados, se encuentra que no existe una inclinación predominante sobre la percepción po- 
sitiva o negativa acerca de las condiciones del entorno de la Universidad. Esto debido en parte a las múltiples ideologías y puntos de vista que existen sobre el enfoque que tiene y debe asumir la UN; para algunos el enfoque utilitarista- empresarial ha permeado la Universidad, relegando la concepción humanista y afectando la calidad de la educación. En contraste, al momento de observar las referencias sobre capacidades internas se denota una favorabilidad a los aspectos positivos con que cuenta la Universidad para desarrollar vinculación con el entorno lustración 4).

Ilustración 4. Percepción de capacidades y condiciones de los entrevistados ${ }^{7}$

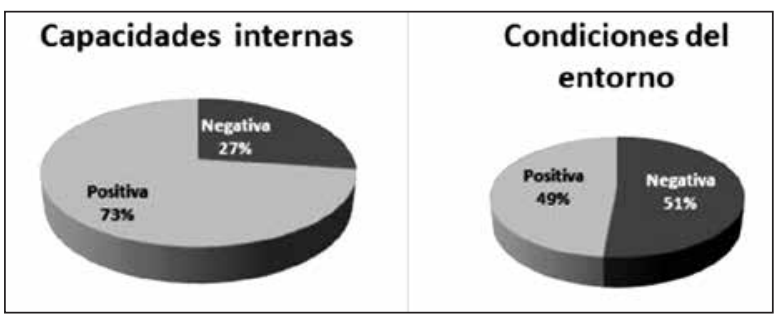

Al revisar las primeras 15 subcategorías analizadas (Tabla 5) se encuentra que las capacidades internas con mayor referencia se concentran en aspectos positivos. En ese sentido, el buen nombre de la universidad es un aspecto de gran importancia, a juicio de los entrevistados, en el momento de crear relaciones con el entorno. La universidad cuenta con una experiencia que la ha consolidado como una de las mejores en el campo académico, hecho que la convierte en referente para las universidades, tanto públicas como privadas del país. Lo anterior se convierte en carta de presentación en el momento de formalizar la vinculación.

De igual modo, el talento humano que integra a la Universidad es clave para desarrollar actividades de calidad frente a la sociedad. Docentes, estudiantes y egresados son el capital que respalda el éxito de las experiencias de vinculación. Los aspectos anteriores se refuerzan con la normatividad y las políticas que rigen y dirigen los alcances de la universidad frente a las necesidades de cada actor del contexto.
Tabla 5. Principales capacidades internas de la UN referenciadas $^{8}$

\begin{tabular}{|l|c|}
\hline \multicolumn{1}{|c|}{ Subcategoría } & N. Referencias \\
\hline $\begin{array}{l}\text { d1.101 Good will, trayectoria, know how, posicio- } \\
\text { namiento y experticia de la Universidad (aspecto } \\
\text { positivo) }\end{array}$ & 94 \\
\hline $\begin{array}{l}\text { D1.27 Recursos humanos idóneos (aspecto po- } \\
\text { sitivo) }\end{array}$ & 74 \\
\hline D1.5 Normatividad (aspecto positivo) & 71 \\
\hline D1.7 Políticas o lineamientos (aspectos positivo) & 67 \\
\hline $\begin{array}{l}\text { D1.21 Aporte de vínculos informales (aspecto } \\
\text { positivo) }\end{array}$ & 63 \\
\hline d1.33 Medios de comunicación (aspecto positivo) & 59 \\
\hline $\begin{array}{l}\text { D1.3 Estructura organizacional administrativa (as- } \\
\text { pecto positivo) }\end{array}$ & 55 \\
\hline D1.11 Planeación (aspecto positivo) & 31 \\
\hline $\begin{array}{l}\text { d1.35 Programación formal de actividades (as- } \\
\text { pecto positivo) }\end{array}$ & 39 \\
\hline $\begin{array}{l}\text { D1.4 Estructura organizacional administrativa (as- } \\
\text { pecto negativo) }\end{array}$ & 33 \\
\hline D1.6 Normatividad (aspecto negativo) & 33 \\
\hline $\begin{array}{l}\text { D1.1 Estructura organizacional académica (aspec- } \\
\text { to positivo) }\end{array}$ & 33 \\
\hline $\begin{array}{l}\text { D1.16 Cultural frente a la comercialización de co- } \\
\text { nocimiento (aspecto negativo) }\end{array}$ & 33 \\
\hline $\begin{array}{l}\text { D1.2 Estructura organizacional académica (aspec- } \\
\text { to negativo) }\end{array}$ & 33 \\
\hline $\begin{array}{l}\text { D1.19 Capacidad de producir conocimiento para } \\
\text { la comercialización (aspecto positivo) }\end{array}$ & \\
\hline
\end{tabular}

Las relaciones informales son catalogadas como un elemento a tener en cuenta en el momento de crear vínculos con organizaciones del entorno, acompañados de medios de comunicación que complementen el trabajo de divulgación de las actividades desarrolladas en el interior de la universidad.

Cuando se observa la percepción que tienen los entrevistados sobre las condiciones del entorno de la $\mathrm{UN}$, las opiniones se encuentran divididas porque más o menos la mitad destaca aspectos positivos y la otra negativos. Así mismo, en las subcategorías indagadas no se identifica un aspecto que sobresalga

$\begin{array}{ll}7 & \text { Fuente: Elaboración propia. } \\ 8 & \text { Fuente: Elaboración propia. }\end{array}$ 
por su mayor importancia en relación a los demás (Tabla 6).

Tabla 6. Principales condiciones externas de la UN referenciadas $^{9}$

\begin{tabular}{|l|c|}
\hline \multicolumn{1}{|c|}{ Subcategoría } & No. Referencias \\
\hline $\begin{array}{l}\text { D2.12 Capacidad de absorción de la industria } \\
\text { (aspecto negativo) }\end{array}$ & 4 \\
\hline $\begin{array}{l}\text { d2.32 Normatividad sector educativo (aspecto } \\
\text { negativo) }\end{array}$ & 4 \\
\hline $\begin{array}{l}\text { d2.48 Nivel de relaciones y vínculos con el sec- } \\
\text { tor público (aspecto positivo) }\end{array}$ & 4 \\
\hline $\begin{array}{l}\text { D2.5 Apoyo gubernamental a sectores estratégi- } \\
\text { cos y de generación de valor (aspecto positivo) }\end{array}$ & 3 \\
\hline $\begin{array}{l}\text { D2.11 Capacidad de absorción de la industria } \\
\text { (aspecto positivo) }\end{array}$ & 3 \\
\hline $\begin{array}{l}\text { D2.22 Existencia de leyes sobre manejo de pro- } \\
\text { piedad intelectual y patentes (aspecto negativo) }\end{array}$ & 3 \\
\hline $\begin{array}{l}\text { D2.23 Diversidad de fuentes de financiación (as- } \\
\text { pecto positivo) }\end{array}$ & 3 \\
\hline $\begin{array}{l}\text { D2.28 Entorno empresarial competitivo (aspecto } \\
\text { negativo) }\end{array}$ & 3 \\
\hline $\begin{array}{l}\text { d2.31 Normatividad sector educativo (aspecto } \\
\text { positivo) }\end{array}$ & 3 \\
\hline $\begin{array}{l}\text { D2.4 Existencia de un conjunto integrado de } \\
\text { políticas en educación, en I\&D, en la implemen- } \\
\text { tación de nuevas tecnologías y política regional } \\
\text { (aspecto negativo) }\end{array}$ & 3 \\
\hline
\end{tabular}

Al analizar los aspectos negativos, el entorno presenta varios que dificultan la interacción de la universidad, principalmente aspectos que se relacionan con los fines económicos de la interacción universidadentorno y entre los que se destacan el nivel capacidad de la industria para aprovechar los procesos de investigación y académicos de las universidades, la legislación del manejo de la propiedad intelectual y el entorno empresarial competitivo.

\section{Reflexiones y conclusiones}

A partir de la revisión teórica y el análisis de los resultados se concluye que existen unas áreas de conocimiento o facultades, como Medicina, Ciencias Económicas, Políticas y Derecho, donde las interac- ciones con el entorno no tienen una pretensión de lucro explícita por parte de la Universidad y que son realizadas principalmente con entidades públicas $u$ organizaciones de tipo social. En concordancia con lo anterior, se hace necesario plantear otra perspectiva de análisis más amplia que el modelo Universidad-Empresa-Estado, agregando un actor adicional que sería la Sociedad, el que no solamente es un agente pasivo que recibe los beneficios del conocimiento generado y transferido si no que a su vez se convierte en un agente activo al hacer parte del proceso que se lleva a cabo para generar y trasferir dicho conocimiento.

La pertinencia de la universidad, dentro del esquema de interacción con el entorno, pasa por el establecimiento de vínculos permanentes, la creación de canales de comunicación claros y confiables, la determinación de estructuras administrativas de apoyo en la interrelación de las capacidades internas y las necesidades del entorno inmediato, la transmisión y difusión del conocimiento generado desde la investigación para generar valor en sectores económicos y la participación directa de la universidad en la solución de los problemas de la sociedad.

Para el logro de una buena interacción de la universidad con el entorno, es importante el compromiso y apoyo de la alta dirección, en la búsqueda vínculos sostenibles, generando estructuras administrativas alejadas de los modelos burocráticos que hacen lentos los procesos de toma de decisiones. El real apoyo de gestión debe centralizar y facilitar el contacto con el usuario externo mediante canales claros de comunicación.

En consonancia con los modelos teóricos que intentan explicar las relaciones universidad-entorno, es claro que las políticas gubernamentales, como directrices reguladoras, inciden en la consolidación de los vínculos entre los diferentes actores de los sistemas científico, tecnológico y de innovación; en referencia a este aspecto, en la actualidad dichas políticas son vistas como un factor positivo que apalanca las creación de canales de vinculación de la universidad y la

9 Fuente: Elaboración propia. 
sociedad. Del mismo modo, la situación económica ha estimulado la asociación de la academia con el sector productivo aprovechando el nivel de estabilidad y necesidad de sostenibilidad de la industria local.

En Colombia la infraestructura de CT +i no ha representado avances significativos como para apropiar los recursos disponibles para la investigación. En este sentido, diversos indicadores posicionan la investigación por debajo de países de la región que invierten un mayor porcentaje de su PIB en $\mathrm{CT}+\mathrm{i}$, igualmente en citaciones, patentes, doctores y autores científicos. Es así como se considera a la universidad colombiana como una entidad dedicada en gran parte a la formación y en menor medida a la investigación (OCDE, 2013). La UN a pesar de ser una universidad líder en Colombia, no escapa a estas fallas estructurales del $\mathrm{CT}+\mathrm{i}$ y muestra cómo las interacciones con el entorno se dan en mayor medida a partir de la docencia.

Por tanto, la universidad debe hacerse partícipe de los problemas que hay en la sociedad. En tal sentido, especialmente en las universidades públicas, la extensión solidaria debe profundizarse mucho más superando la extensión mediante consultoría dirigida a las organizaciones de carácter privado. En el momento que la extensión social se materialice en proyectos con mayor regularidad existirá un mayor prestigio y se generará una imagen más favorable que le facilite a la universidad tener incidencia en integrantes de la sociedad que aún no se benefician del trabajo de la academia.

El papel crítico de los miembros de la universidad se convierte en un factor de debate sobre la posición y rol que debe asumir la universidad frente a su función de extensión, debido a que ella se encuentra actualmente, según algunos entrevistados, bajo las pautas de la privatización de la universidad pública y que parece traída de modelos de educación que no tienen en cuenta la supremacía de la misión social de la universidad en relación con la generación de utilidades para sectores privados de la sociedad. Mientras para unos la universidad debe fortalecer su enfoque empresarial, para otros lo que debe primar es su enfoque humanista, razón por la cual se debe trabajar en la construcción del perfil que se le quiere dar a cada universidad frente a la interacción con la sociedad.

\section{Referencias}

Acevedo, M., González, O., Zamudio, L., Abello, R., Camacho, J., Gutiérrez G., Barreto, E., Ochoa, J., Torres, G., Quintero, M. \& Baeza, Y. (2005). Un análisis de la transferencia y apropiación del conocimiento en la investigación de Universidades Colombianas. En: Investigación \& Desarrollo, 13(1): 128-157.

Arocena, R. \& Sutz, J. (2000). La universidad latinoamericana del futuro. México D.F.: Unión de Universidades de América Latina.

Arocena, R. \& Sutz, J. (2009). Sistemas de innovación e inclusión social. En: Pensamiento Iberoamericano, 5(2): 99-120.

Barré, R. (1995). Hacia una "inteligencia" de los sistemas sociales de innovación: problemas, condiciones y perspectivas. En: Redes, 2(4): 13-27.

Brundin, E., Wigren, C., Isaacs, E., Friedrich, C. \& Visser, K. (2008). Triple helix networks in a multicultural context: triggers and barriers for fostering growth and sustainability. En: Journal of Developmental Entrepreneurship, 13(1): 77-98.

Buesa, M. (2002). El sistema regional de innovación de la Comunidad de Madrid. Documento de trabajo N ${ }^{\circ} 30$. Instituto de Análisis Industrial y Financiero. Madrid: Universidad Complutense.

Buesa, M., Martínez, M., Heijs, J. \& Baumert, T. (2002). Una tipología de los sistemas regionales de innovación en España. Una tipología basada en indicadores económicos e institucionales. En: Economía Industrial, 347(V): 15-32.

Claves para el debate público (2010). Universidad, Empresa y Estado en Colombia, altos y bajos en la transferencia del conocimiento en menos de una década. Universidad Nacional de Colombia, Bogotá.

Colciencias (2006). 75 maneras de generar conocimiento en Colombia. Bogotá: Colciencias.

CONNECT (2013). Conózcanos - Historia. Recuperado el 13 de abril de 2013 de: http://www.connectbogota.org/conocenos\#

Etzkowitz, H. (1998). The norm of entrepreneurial science: cognitive effects of the new university-company linkages. En: Elsevier Science, 27: 823-833.

Etzkowitz, H. \& Leydesdorff, L. (1996). Emergence of a triple helix of university- industry-government relations. En: Science and Public Policy, 23: 279-286.

Etzkowitz, H. \& Leydesdorff, L. (2000). The dynamics of innovation: from national systems and 'mode 2' to a triple helix of university-industry-government relations. En: Research Policy, 29(2): 109-123.

Etzkowitz, H., Webster, A., Gebhardt, C. \& Cantisano, B. (2000). The future of the university and the university of the future: evolution of ivory tower to entrepreneurial paradigm. En: Research Policy, 29(2): 313-330.

Freeman, C. (1987). Technology policy and economic performance: lessons from Japan. Londres: Pinter.

García, R. (2008). Análisis teórico de la transferencia de conocimientos universidad-empresa mediante la colaboración. En: Economía: teoría y práctica, Nueva Época, 29: 51-86.

González de la Fe, T. (2009). El modelo de triple hélice de relaciones universidad, industria y gobierno: un análisis crítico. En: ARBOR Ciencia, Pensamiento y Cultura, 738: 739-755. 
López, G. (2004). Aproximación a las generalidades y debilidades del sistema de innovación colombiano. En: Scientia Et Technica, X (24): 195-200.

López, R. \& Deslauriers, J. (2011). La entrevista cualitativa como técnica para la investigación en trabajo social. En: Margen, 31: 1-19.

Lundvall, B. (1997). National systems and national styles of innovation. Fourth International ASEAT Conference Differences in 'styles'. Manchester.

Martínez, P. (2006). El método de estudio de caso: estrategia metodológica de la investigación científica. En: Pensamiento \& Gestión, 20: 165-193.

Morales, M., Sanabria, P., Caballero, D. \& Fandiño, F. (2012). Categorías de análisis de la vinculación universidad y entorno. Documento de trabajo, proyecto ECO-919. Bogotá: Grupo de Estudios Contemporáneos en Contabilidad, Gestión y Organizaciones, Universidad Militar Nueva Granada.

Mejía, A. (2009). La investigación en ciencias sociales y humanas bajo el esquema del modelo universidad - empresa - Estado: una mirada desde la teoría crítica de la sociedad. En: Revista Interamericana de Bibliotecología, 32(2): 231-252.

OCDE, IBRD \& The World Bank (2013). Investigación e innovación en Colombia. En: Evaluaciones de políticas nacionales de educación: la educación superior en Colombia. OECD Publishing. Disponible en: http://dx.doi.org/10.1787/9789264180710-10-es

Pedraza, L. (2013). Caracterización de experiencias y estrategias de la vinculación universidad, empresa y Estado en las facultades de derecho y medicina de la Universidad Nacional de Colombia. Tesis presentada en cumplimiento de los requisitos para el título de Magister en Gestión de Organizaciones, Universidad Militar Nueva Granada.

Pineda, K., Morales, M. \& Ortíz, M. (2011). Modelos y mecanismos de interacción universidad-empresa-Estado: retos para las universidades colombianas. En: Equidad y Desarrollo, 15: 41-67.

Ramírez, M. \& García, M. (2010). La alianza Universidad-EmpresaEstado: una estrategia para promover innovación. En: Revista EAN, 68: 112-133.
Ruiz, J., Castaño, V., Pastrana, A., García, M., Ruiz, J. \& Zagal, J. (2011). Cuerpo académico INNOVAX: gestión del conocimiento y creación de valor en la sociedad. En: XI Encuentro Nacional Académico en Administración de Agronegocios y Disciplinas Afines. Coahuila de Zaragoza.

Sábato, J. (1979). Ensayos en campera. Ciudad de Buenos Aires: Juárez Editor.

Sábato, J. \& Botana, N. (1968). La ciencia y la tecnología en el desarrollo futuro en América Latina. En: The World Order Models Conference. Bellagio, Italia.

Scudelati, M. (2007). El triángulo de Sábato: marco teórico para la gestación del polo tecnológico Bahía Blanca. En: XII Seminario Latino-Iberoamericano de Gestión Tecnológica - ALTEC 2007. Buenos Aires.

Touriñan, J. (2005). Universidad, sociedad y empresa: orientaciones estratégicas de extensión universitaria y comunicación institucional. Visión prospectiva desde el marco legal español. En: Revista Galego-Portuguesa de Psicoloxía e Educación, 10(12): 163-186.

UNESCO (2011). Revisión de la Clasificación internacional normalizada de la educación - CINE. UNESCO.

UN (2013). Alianza universidad-empresa-Estado Bogotá región. Dirección de extensión sede Bogotá. Bogotá: UN. Recuperado 10 de mayo de 2013 de: http://www.unal.edu.co/extensionbog/ paginas/integracion/comite_cuee.html

Vázquez, R., Mateos, J. \& Lucero, M. (2013). El modelo humanista integrador basado en competencias (MHIC) de la UATx ante las políticas educativas para la educación superior. En: Foro Internacional sobre el papel de las Humanidades y el humanismo en la universidad contemporánea. Nuevo León.

Villaveces, J. (2006). Nuevas políticas de ciencia y tecnología. En: CLACSO, Universidad e Investigación Científica. Buenos Aires: Consejo Latinoamericano de Ciencias Sociales.

Younes, J. (2002). El concepto de la universidad y sus funciones en el siglo XXI. Bogotá D.C.: ECOE Ediciones. 